\title{
Human Rights as a Lens for Engineering Ethics?
}

\section{Dr. Angela R. Bielefeldt, University of Colorado, Boulder}

Angela Bielefeldt is a professor at the University of Colorado Boulder in the Department of Civil, Environmental, and Architectural Engineering (CEAE). She has served as the Associate Chair for Undergraduate Education in the CEAE Department, as well as the ABET assessment coordinator. Professor Bielefeldt was also the faculty director of the Sustainable By Design Residential Academic Program, a livinglearning community where interdisciplinary students learn about and practice sustainability. Bielefeldt is also a licensed P.E. Professor Bielefeldt's research interests in engineering education include servicelearning, sustainable engineering, social responsibility, ethics, and diversity. 


\title{
Human Rights as a Lens for Engineering Ethics?
}

\begin{abstract}
This paper illustrates how the United Nations Universal Declaration of Human Rights can be used to frame engineering ethics discussions. Examples are provided for how engineering ethics relates to the rights to: nondiscrimination, life and security of persons, privacy, property ownership, work, and a basic standard of living. The recent Statement on Scientific Freedom and Responsibility from the American Association for the Advancement of Science was rooted in the right to science and recognizes the important link between freedom and responsibility. This philosophy includes attention to the broader impacts of research activities and argues against higher education tenure and promotion criteria that preference self-serving academic outcomes over real-world benefits and engagement. The practices of engineering education itself are probed in relation to Article 26 on the right to education, in terms of accessibility and promoting peace. The paper provides many ways in which engineering ethics can be examined through the lens of universal human rights. This framework may resonate with students interested in care and helping people and society. Educators may wish to examine whether a human rights lens is relevant to their teaching.
\end{abstract}

\section{Introduction}

This paper will illustrate how the United Nations'1948 Universal Declaration of Human Rights (UDHR) [1] can be used to frame ethics discussions in engineering. Engineering ethics in the U.S. are not typically taught or framed through the lens of human rights. A few notable exceptions include calls from Lynch [2] and Hoole [3] near the end of the United Nations' Decade on Human Rights Education (1995-2004). A human rights framework may be useful and bring engineering more in line with traditions in other professions. The paper first discusses professional ethics through a human rights lens, briefly comparing and contrasting different professions. Next the paper discusses how engineering relates to specific human rights articulated in articles from the UDHR. For each of these rights, cases suitable for engineering ethics education are provided. The paper concludes with a consideration of limitations and broader issues.

\section{Human Rights and Professional Ethics}

It has been asserted that "the concept of human rights is widely recognized but perhaps poorly understood in the United States" [4, p. 3]. Americans tend to think more narrowly of "civil and political rights defined in the U.S. Bill of Rights" [5], rather than the more extensive rights encompassed within the UDHR. Human rights education (HRE) is a movement: ...in 1974 the United Nations Educational, Scientific and Cultural Organization (UNESCO) adopted a document explicitly supporting education for human rights (UNESCO 1974), it took two more decades before interest in HRE would be revived in any serious manner within the United Nations... [such as] the United Nations Decade for Human Rights Education 1995-2005. In 2011, ...the UN Declaration on Human Rights Education and Training (DHRET) [was passed] ... [4, p. 6]

HRE seems most rooted in legal education, but has been expanding "so that it is no longer the purview of only lawyers" [4, p. 5]. Marks [6] explored the relationship between professional ethics and human rights, but focused primarily on law, medicine, and psychology. The 
disciplines of social work, health sciences (medicine, nursing), and teacher education were the most common among 64 peer-reviewed articles that were identified using a search in the Web of Science citation index using the search terms "human rights education" and "university" (Jan. 20, 2019). None of the 64 abstracts included the word "engineer*"; comput* only appeared once, related to faculty in a Computer Education Department participating in a workshop on HRE. The majority of the 64 articles originated from authors and contexts at higher education institutions outside the U.S. (e.g. Korea $\mathrm{n}=22$, U.S. $\mathrm{n}=7$ (but 2 of these authors studying non-U.S. contexts), Brazil $n=5$, Turkey $n=3$, Canada $n=3$, China $n=2$, South Africa $n=2$, Colombia $n=2$, Germany n=2; 1 each: Algeria, Australia, Iran, Israel, Jordan, Malaysia, Mexico, Norway, Peru, Philippines, Portugal, Spain, Sweden, Switzerland, Thailand, Uruguay). This country-based analysis supports the assertion that HRE is less common in higher education in the U.S.; individuals with an interest in HRE may need to look outside the U.S. for models. A search in Web of Science using the topics ethics AND education AND "human rights" yielded 822 results, but the majority of these were in K-12 contexts rather than higher education.

\section{Human Rights and Engineering Ethics}

Within engineering, ethics education is grounded in multiple ethical theories. A review of ten engineering ethics textbooks and three introduction to engineering textbooks that included ethical theories found utilitarianism in all thirteen, virtue ethics in eleven, rights ethics and duty ethics in nine, ethical egoism in five, and care ethics in two [7]. Thus, rights ethics are among the more common theories used to ground ethics education. However, this does not always translate into calling on the UDHR. In regards to rights-based theories, Catalano [8] briefly discussed notions of justice, Locke's "life, liberty, and property" and cited "universal human rights". However, further elaboration was not provided, since the intent of the chapter that discussed theoretical foundations was to provide alternative frameworks (e.g. morally deep world, love, globalism). Fledderman [9] frames rights ethics as individuals possessing "fundamental rights that others have duties to protect", again citing Locke and the Declaration of Independence. This puts a somewhat U.S.-centric spin on rights ethics. The UDHR is not mentioned. Challenges that arise when individual rights come into conflict are discussed through examples. Thus, the rights foundations applied within engineering ethics education in the U.S. do largely conform to the narrower civil and political rights common in U.S. schools as described by Tibbets [4].

Human rights and engineering education intersections have been examined by a number of individuals. The number of peer reviewed publications found via different search processes are summarized in Table 1. Some of these papers represent theoretical considerations, while others are examples of applications in teaching settings. The Web of Science results analysis characterized the 357 references from the search on "human rights" AND engineering into the categories of: sociology 189; genetics heredity 166, medical ethics 141 , government law 113 , social issues 96 , philosophy 89 , psychology 88 , health care sciences services 86 , behavioral sciences 81 , and engineering 69 . This indicates that other disciplines commonly explore intersections among engineering / technology and human rights. Comparing the number of articles published in the European Journal of Engineering Education with the Journal of Engineering Education (affiliated with the American Society for Engineering Education, ASEE), those outside the U.S. seem to more frequently explore intersections among human rights and engineering. 
Table 1. Literature Search Results Summary

\begin{tabular}{|c|c|c|c|c|}
\hline Source & Search Terms & $\mathrm{n}$ & HR in Title, $n$ & Years \\
\hline Web of Science & $\begin{array}{l}\text { "human rights education" + } \\
\text { university }\end{array}$ & 64 & 42 & $2004-2019$ \\
\hline Web of Science & "human rights" + engineering & 357 & 46 & $1972-2019$ \\
\hline Web of Science & $\begin{array}{l}\text { "human rights" + engineering } \\
+ \text { education }\end{array}$ & 41 & 4 & $1974-2018$ \\
\hline $\begin{array}{l}\text { EJEE - European Journal of } \\
\text { Engineering Education }\end{array}$ & "human rights" & 23 & 0 & $1985-2019$ \\
\hline $\begin{array}{l}\text { JEE - Journal of Engineering } \\
\text { Education }\end{array}$ & "human rights" & 2 & 0 & 1996-1998 \\
\hline ASEE PEER & "human rights" & 119 & 2 & 1996-2018 \\
\hline $\begin{array}{l}\text { Science \& Engineering Ethics } \\
\text { journal }\end{array}$ & "human rights" & 200 & 7 & $1995-2018$ \\
\hline
\end{tabular}

Publications exploring intersections among human rights and engineering over the past two decades are increasing (Figure 1). Illustrative of increased interest is a postdoctoral fellowship on human rights for engineering at the University of Connecticut [10]. The American Association for the Advancement of Science (AAAS) is actively exploring intersections between engineering and human rights [11]. Wyndham's 2012 webinar is an excellent overview [11]. During that webinar, the majority of individuals participating in a live poll felt that "engineers and applications of engineering may negatively impact human rights" (94\%) with somewhat fewer agreeing that "engineers can apply their skills to human rights" $(89 \%)$.

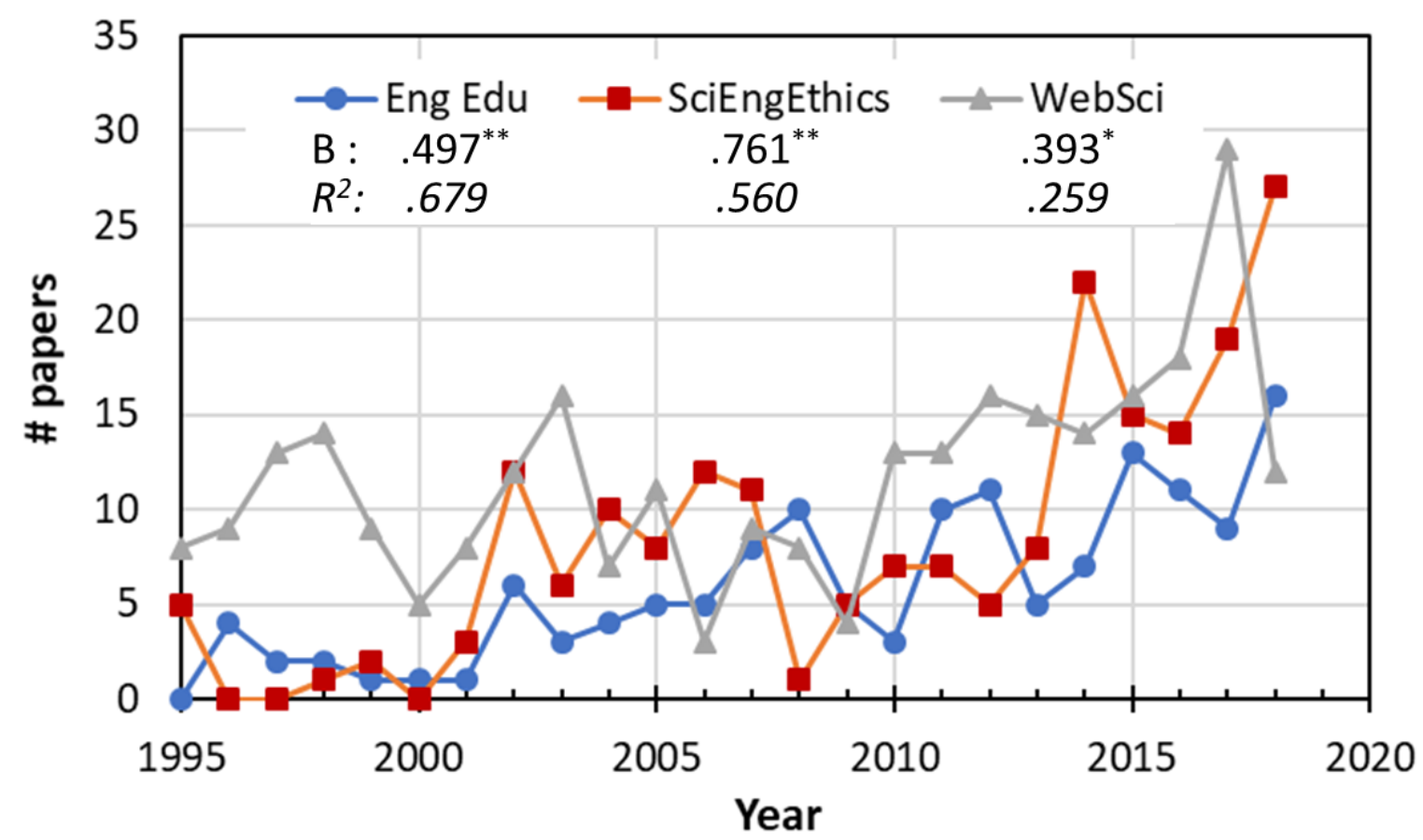

Figure 1. Number of papers published per year, using sources and search terms in Table 1 (Eng $\mathrm{Edu}=\mathrm{ASEE}$ PEER + EJEE + JEE; WebSci = "human rights" + engineering); linear regression coefficients and $\mathrm{R}^{2}$ shown, ${ }^{* *} \operatorname{sig} .<.001 ;{ }^{*}=\operatorname{sig} . .011$ 
Despite the characterization of the UN UDHR as "universal human rights" not all of the articles are uniformly accepted across all countries as legally guaranteed rights. The UDHR was the basis for two international laws (International Covenant on Civil and Political Rights and International Covenant on Economic, Social, and Cultural Rights; adopted 1966, entry in force 1976; ratified by 172 and 169 countries, respectively) and subsequent treaties from the United Nations have further elaborated on human rights related to race, women, children, torture, disabilities, and others [12]. Comparison among human rights perceptions / conditions in different countries is relevant given the increasingly global nature of engineering activities [1315]. Acknowledging and discussing these differences is also appropriate given the different backgrounds and nationalities of students in our engineering classes; international students earned 9.6\% of engineering Bachelor's degrees and 58.1\% of engineering Master's degrees in 2015-2016 [16]. Cheng [17] also discusses differences among the UN declaration and determinations in U.S. courts, which have not uniformly supported the rights in all of the articles (e.g. "standard of living adequate for health", Article 25).

The following sections review selected individual articles within the UDHR, exploring relations to engineering and how these ideas might be integrated into teaching.

\section{Nondiscrimination - Article 2}

The second article in the UDHR states that "everyone is entitled to rights and freedoms... without distinction" based on various demographic factors including race, sex, and other factors [1]. Engineering has been examining its practices related to diversity and inclusion for many years, including access to education (described more fully below) and equity in design. Recently, this idea has found its way into engineering codes of ethics from the American Society of Civil Engineers (ASCE) [18], the Institute for Electrical and Electronics Engineers (IEEE) [19], and the American Institute of Chemical Engineers (AIChE) [20]. Other groups have endorsed ideas around diversity, but not yet situated these responsibilities within their code of ethics (e.g. the National Society of Professional Engineers, NSPE [21, 22]; American Society of Mechanical Engineers, ASME [23, 24]).

If instructors wish to address issues of discrimination or diversity in their courses, there are teaching cases available. The ASCE cases related to discrimination in the workplace and among faculty [25-27] may serve as good teaching cases and/or discussion topics. Design-related choices can also impact equity, in ways that are generally unintentional but nevertheless important. Examples of equity and non-discrimination in design relate to transportation planning (civil engineering) [28], assistive technology [29], universal accessibility for people with physical limitations [30], and artificial intelligence [31]. These design-related issues could be readily integrated into a number of technical courses for a wide array of engineering disciplines.

\section{Right to Life and Security of Person - Article 3}

Article 3 of the UDHR states, "Everyone has the right to life, liberty and security of person" [1]. Technology is being used to document human rights abuses via tools including satellite imagery, remote sensing, and machine learning. Artificial intelligence, autonomous agents, and machine learning can also be applied in numerous ways that have potential benefits and harms with respect to human rights $[32,33]$. For example, autonomous weapon systems have the potential to 
be used in violating this right to life and personal security [34]. Students can be encouraged to consider the trade-offs of these technologies in light of the UDHR Article 3.

\section{Right to Privacy- Article 12}

Article 12 indicates that "no one shall be subjected to arbitrary interference with [their] privacy" [1]. Privacy concerns are significant in relation to electronic data (particularly in terms of how this data can be accessed via the internet) and biometric technologies applied to security/ surveillance cameras. Privacy issues are garnering lots of attention [31, 35, 36]; for example, 76 papers in the Science and Engineering Ethics journal were found using a keyword search on "human rights" AND privacy. Privacy is also a key issue in computing education, being required under the ABET Computing Accreditation Commission's criteria (5. Curriculum, (a)2.d. Human security) [37] and recommended for computer engineering education (e.g. in the ACM/IEEE's Curricular Guidelines [38], privacy is found among the Preparation for Professional Practice outcome 9, contemporary issues). A general discussion of scenarios and issues related to ethics and privacy is provided by Britz [39] from the perspective of an information professional. Human rights are discussed as one of three ethical norms applicable to privacy (also including truth and freedom). The paper is written in a style that should be interesting and accessible to students and is not overly long. However, it is somewhat dated. The paper could form the basis for in-class discussion or a written reflection if an instructor generated appropriate prompts. There are also more detailed case studies related to privacy that would be good vehicles for instruction, including Google Street View [40, 41] and "optimizing schools" [42]. These cases do not explicitly discuss a human rights perspective, so this framing would need to be added by the instructor.

\section{Right to Property - Article 17}

Article 17 relates to the right to own and not "be arbitrarily deprived of [ ] property" [1]. This relates to civil engineering and the use of eminent domain for projects, which is of global concern [43]. Eminent domain is often examined from a legal perspective [e.g. 44, 45]. There are generally design alternatives that can avoid taking property for infrastructure projects, but these options may not to be exercised equally in locations of different affluence [44]. The NSPE [46] has a short (3 page) case study which includes issues of eminent domain that could be suitable for educational purposes. The official analysis cites the NSPE code of ethics, but the instructor could broaden the discussion to bring in the notion of the human right to property. A current events approach could be more relatable to students, using timely examples in the local community to spur discussion. One example is a recent situation in Seattle where eminent domain was being used by the local transit authority to take land to build a parking garage [47]. The article discusses "four of those [six] alternatives did not involve taking any land from the lodge", which allows engineers to see how their analysis is impactful.

\section{Right to Work - Article 23}

Article 23 broadly encompasses the right to fair and decent work. Automation, robotics and artificial intelligence (AI) may impact this right [36, 48-50]. An extensive and critical analysis of the broad issues of how technology impacts the right to work was recently published [48]. A particularly relevant section explores the "impact of technology on the number and quality of jobs" [48, p. 27-30], and is a reasonable reading assignment for students. It offers multiple perspectives, including that technological progress will result in "massive job losses and 
exacerbate inequality", and the opposing perspective that the result will be "more and better jobs." These assertions are supported with numerous citations to other studies. A more narrow approach was taken by McGregor et al. [49], who discussed three ways that "AI can create or exacerbate inequality in access to the right to work" [p. 19-21]. This portion of the larger document could be used as a reading to stimulate student discussion. By comparison, the popular press pieces offer limited depth $[36,50]$.

Article 23 also includes the right to equal pay for equal work. Explorations have found that women engineers earn about $90 \%$ of the salary of their male peers [51]. The differences vary by discipline, being very small in biomedical (98\%) and the largest in civil, aerospace, electrical engineering and software development (86\%) [US Census Bureau 2016 data cited in 51]. This may be an uncomfortable conversation in a typical engineering course, but the issue is certainly appropriate in a co-curricular setting such as a meeting of the Society of Women Engineers. Students could read [51] and discuss. This could be complemented by highlights from Cech's paper that studied differences among job roles within engineering [52].

\section{Right to a Basic Standard of Living - Article 25}

Article 25 states, "Everyone has the right to a standard of living adequate for the health and wellbeing of himself and of his family, including food, clothing, housing and medical care ..." [1]. This right is relevant to engineering in a number of ways. It can be argued that a large portion of the world's population is below an adequate standard of living, and engineering can play a role in providing these basic services like access to clean water, sanitation, and housing $[53,54]$. Kaminsky et al. [55] recently framed their water and wastewater infrastructure services work in the context of human rights. While the previous issues are largely the domain of civil, architectural, and environmental engineering, biomedical and mechanical engineering are directly applicable to the right to medical care. Lynch [2] discusses the importance of acknowledging this right as a foundation for the engineering profession.

\section{Enjoy the Benefits of Scientific Advancement - Article 27}

Article 27 includes the "right... to share in scientific advancement and its benefits" [1]. It formed the basis for the 2017 Statement on Scientific Freedom and Responsibility from the American Association for the Advancement of Science (AAAS) [56, 57]. The statement defines scientific freedom and notes that it "is inextricably linked to and must be exercised accordance with scientific responsibility." Given the potential for social benefits and harms from scientific and engineering endeavors, acknowledging the linkage between responsibility and freedom is important $[57,58]$. The AAAS identified a number of themes that they believe are relevant to the statement including the ethical conduct of science, science integrity, freedom to conduct research, and responsibilities, highlighting particular topics such as bioethics, conflict of interest, reproducibility, bioterrorism and security, peer review, etc. [59]. Articles published in Science from 1986 to present that map to each of these themes are compiled on a website [59], with earlier articles indexed in a separate list [60]. These articles are typically short and could provide good readings for students to stimulate discussion.

The link between freedom and responsibility is particularly important with reference to research, and aligns with attention to the broader impacts of research activities that are a necessary consideration in funding awarded by the National Science Foundation [61]. More broadly, these 
responsibilities argue against higher education tenure and promotion criteria that preference selfserving academic outcomes (e.g. citations by other academics) over real-world benefits and engagement [62]. Discussing these issues would be particularly relevant in graduate-level courses. This could spark more robust debate than responsible conduct of research topics that are more typically discussed in graduate-level engineering courses.

\section{Responsibility - Article 29}

Article 29 has been characterized as responsibility [63], based on the notion that "everyone has duties" to others [1]. This aligns with the notion of social responsibility and engineers' beliefs about their responsibilities to others [64-66]. Groups such as Engineers for Social Responsibility in New Zealand support this idea [65]. In addition, broader initiatives demonstrate the commitment of engineering to this idea, such as IEEE's Ethically Aligned Design [67] and the Internet Engineering Task Force and Human Rights [68]. Fostering these feelings of social responsibility among engineering students is described more fully below in reference to Article 26.

\section{Right to Education - Article 26}

The practices of engineering education itself can be probed in relation to Article 26 on the right to education. On the plus side, online learning such as massive open online courses (MOOCs) and the use of technology can help expand both access to education and the quality of education $[36,69]$. But a broader array of factors warrant consideration. Higher education costs in the U.S. have been rising at a rate outpacing inflation $[70,71]$, reducing affordability. This has led to an examination of the worth of college degrees from the perspective of return on investment for individuals, society, and colleges [71-73]. These analyses tend to neglect the non-monetary benefits of education. However, cost considerations are important given that engineering degrees tend to require more credits, which may translate into longer average time to degree $[74,75]$. Adding in widely varying costs $[71,76]$, higher education institutions can critically examine whether its practices make it equally accessible to those of varying socio-economic status.

Another element in the right to education is that "higher education should be equally accessible to all on the basis of merit" [1]. Engineering may or may not generally be meeting this goal, considering that admissions practices frequently rely to a large extent on standardized tests known to be biased against some groups [77, 78]. Bias can operate both for and against underrepresented or historically marginalized groups in both admissions and support programs [79 81].

Is engineering education "directed to the full development of the human personality"? [1] One could interpret this as liberal education, and attention to the whole person $[82,83]$. However, engineering education has been criticized as being narrowly focused on technical facets and job skills at the detriment of this wider perspective [74, 84].

To what extent do most engineering programs contribute "to the strengthening of respect for human rights and fundamental freedoms"? [1] Do our programs "promote understanding, tolerance and... the maintenance of peace"? [1] Some individuals and groups are dedicated to these aims, including Engineering Social Justice and Peace and others [2, 3, 65, 66, 85-87]. 
However, the culture of disengagement characterized in engineering education seems counter to these aims [88].

\section{Critique}

There are a number of limitations of using the original UDHR as the basis for grounding ethics education within engineering. First, the UDHR has a primarily individualistic focus, seeming to neglect collective rights, such as those of indigenous peoples and cultures grounded in holistic community over the individual [4]. It also fails to acknowledge the importance of the environment and considering the natural ecosystem upon which all life relies. This is not surprising given that the document originated in 1948 - just after World War II and pre-dating a recognition of the impact of environmental degradation on human health and well-being and broader environmental ethics movements. As such, students should be encouraged to consider the historical context of the UDHR and this should not be the sole grounding of engineering ethics education. The human rights context can draw attention to the social aspects of sustainability, but critically considering stewardship of natural resources [2] and ecocentric ideas should also be embraced.

Given the age of the UDHR, newer documents that embrace human rights perspectives should also be explored. Hertel and MacKay [89] included the UN Guiding Principles on Business and Human Rights and sustainability themes within an interdisciplinary course for students in engineering, social sciences, and humanities. A comparative approach to teaching human rights may also be effective [90]. A large array of resources are available to help instructors with an interest in integrating human rights perspectives into their teaching, including examples in engineering (Table 1) and beyond; international models are more common. Engineering students may also learn about human rights via humanities and social science electives, and integrating this language into engineering courses may help bridge these areas.

\section{Conclusion}

Engineering ethics can be readily taught using a human rights lens. Some provisions are more relevant to particular engineering disciplines. A human rights approach could be compared to other ethical perspectives (e.g. utilitarianism). The language of human rights is well aligned with other professions such as law. Teaching a human rights framework in engineering might make it easier when engineers interact with other professions (e.g. biomedical engineers and doctors working together in the field of medicine). The current paper is not exhaustive in terms of examples of how human rights issues relate to engineering and engineering education. However, it is intended to give educators issues to consider and resources to get started if they are interested. Beyond considering how we can teach engineering students about human rights, we may also wish to more broadly examine educational practices in engineering at our institutions in alignment with the aims of the right to education in Article 26.

\section{References}

[1] United Nations (UN), Universal Declaration of Human Rights. 1948. https://www.ohchr.org/EN/UDHR/Documents/UDHR_Translations/eng.pdf [Accessed October 21, 2018 ].

[2] D.R. Lynch, "A human rights challenge to the engineering profession." Proceedings of the American Society for Engineering Education Annual Conference \& Exposition, 2004, 9 pp.

[3] D. Hoole and S.R.H. Hoole, "A curriculum with human rights in an engineering program and its implementation," Proceedings of the American Society for Engineering Education Annual Conference \& Exposition, 2002, 8 pp. 
[4] F. Tibbitts, "Building a human rights education movement in the United States," in S.R. Katz and A.M. Spero, Eds. Bringing Human Rights Education to US Classrooms: Exemplary Models from Elementary Grades to University. New York: Palgrave Macmillan, 2015. pp. 3-14.

[5] N. Flowers and K. Rudelius-Palmer, "An introduction to human rights education," Human Rights Education Here and Now: Celebrating the Universal Declaration of Human Rights. http://hrlibrary.umn.edu/edumat/hreduseries/hereandnow/Part-2/HRE-intro.htm [Accessed Jan. 28, 2019]

[6] J.H. Marks, "Toward a unified theory of professional ethics and human rights," Michigan Journal of International Law, vol. 33, pp. 215-263, 2012.

[7] A. Bielefeldt, "Ethic of care and engineering ethics instruction," Proceedings of the American Society for Engineering Education (ASEE) Rocky Mountain Section Conference, April 10-11, 2015. Denver, CO. 7 pp.

[8] G.D. Catalano. Tragedy in the Gulf: A Call for a New Engineering Ethic. Morgan \& Claypool Publishers. 2011.

[9] C.B. Fleddermann, Engineering Ethics, $4^{\text {th }}$ Edition, Upper Saddle River: Prentice Hall, 2012

[10] Postdoctoral Fellowship on Human Rights for Engineering, REPOSTED June 8, 2018, University of Connecticut; https://chroniclevitae.com/jobs/0000428547-01; [Accessed Jan. 29, 2019]

[11] J. Wyndham, Engineering for Human Rights: Opportunities, Risks and Responsibilities. Webinar, Engineering for Change, AAAS, ASME. June 13, 2012. https://www.engineeringforchange.org/webinar/video-engineeringfor-human-rights/ [Accessed Jan 29, 2019]

[12] United Nations (UN). Office of the High Commissioner of Human Rights. http://www.un.org/en/sections/whatwe-do/protect-human-rights//Accessed Jan. 29, 2019]

[13] S. McFarland, "International differences in support for human rights," Societies Without Borders, vol. 12 (1), pp. 21. Available at: https://scholarlycommons.law.case.edu/swb/vol12/iss1/12 [Accessed Jan. 28, 2019].

[14] H. Rindermann and N. Carl, "Human rights: Why countries differ," Comparative Sociology, vol. 17, pp. 29-69, 2018. DOI: $10.1163 / 15691330-12341451$, http://booksandjournals.brillonline.com/content/journals/10.1163/15691330-12341451

[15] United Nations, Human Rights, Office of the High Commissioner. https://www.ohchr.org/EN/Issues/Pages/ListOfIssues.aspx [Accessed Jan. 28, 2019]

[16] B.L.Yoder. Engineering By the Numbers. American Society for Engineering Education. 2016.

[17] T-H. Cheng, "The Universal Declaration of Human Rights at sixty: Is it still right for the United States?" Cornell International Law Journal, vol. 41 (2), article 2, 57 pp., 2008.

[18] American Society of Civil Engineers, ASCE. Code of Ethics. July 29, 2017. https://www.asce.org/code-ofethics/ [Accessed Jan. 29, 2019].

[19] Institute of Electrical and Electronics Engineers, 7.8 IEEE Code of Ethics. (2017). 〈https://www.ieee.org/about/corporate/governance/p7-8.html〉 [Accessed Jan. 29, 2019].

[20] American Institute of Chemical Engineers, AIChE Code of Ethics, Board approved November 2015. https://www.aiche.org/about/code-ethics [Accessed Jan. 29, 2019].

[21] National Society of Professional Engineers, NSPE, "Minorities and women in engineering. NSPE position statement No. 1740.” NSPE Diversity Statement, 2000. 〈https://www.nspe.org/resources/issues-andadvocacy/take-action/position-statements/minorities-and-women-engineering (Feb. 23, 2017)

[22] National Society of Professional Engineers, NSPE Code of Ethics for Engineers, as revised July 2018, Alexandria VA: NSPE. https://www.nspe.org/resources/ethics/code-ethics [Accessed Jan. 29, 2019].

[23] American Society of Mechanical Engineers, ASME, Diversity Statement. (2016). "Diversity and inclusion in the science, technology, engineering, \& mathematics (STEM) workforce: A strategic global imperative." 〈https://www.asme.org/wwwasmeorg/media/ResourceFiles/AboutASME/PS16-02.pdf〉 (Feb. 22, 2017)

[24] American Society of Mechanical Engineers, Society Policy P-15.7, Code of Ethics of Engineers. Adopted Feb. $1,2012$. https://www.asme.org/wwwasmeorg/media/ResourceFiles/AboutASME/Get\%20Involved/Advocacy/PolicyPublications/P-15-7-Ethics.pdf [Accessed Jan. 29, 2019].

[25] American Society of Civil Engineers, ASCE, Discrimination allegation would fall under new canon. Sept 1, 2017. https://www.asce.org/question-of-ethics-articles/sep-2017/ [Accessed Jan. 28, 2019]

[26] American Society of Civil Engineers, ASCE, Practicing the principles of equitable participation. Oct. 1, 2018. https://www.asce.org/question-of-ethics-articles/oct-2018/ [Accessed Jan. 30, 2019].

[27] American Society of Civil Engineers, ASCE, Female engineer faces workplace discrimination. Jan 1, 2008 https://www.asce.org/question-of-ethics-articles/jan-2008//Accessed Jan. 28, 2019]

[28] B. van Wee and K. Geurs, "Discussing equity and social exclusion in accessibility evaluations," EJTIR, vol. 11(4), pp. 350-367, Sept. 2011. 
[29] A. Ezeiza, N. Garay, K. Lopez de Ipina, A. Soraluze, "Ethical issues on the design of assistive technology for people with mental disabilities," International Conference on Ethics and Human Values in Engineering, Barcelona 2008. 10 pp.

[30] G.C. Vanderheiden and J.B. Jordan, "Chapter 51: Design for people with functional limitations," in Handbook of Human Factors and Ergonomics $4^{\text {th }}$ Edition, Ed. G. Salvendy, John Wiley \& Sons, 2012.

[31] M. Latonero, "Governing artificial intelligence: Upholding human rights \& dignity," Data \& Society. 37 pp. https://datasociety.net/wpcontent/uploads/2018/10/DataSociety Governing_Artificial_Intelligence Upholding Human Rights.pdf [Accessed Jan. 30, 2019].

[32] T.L. Harris, J. Drake, J. Wyndham, S.R. Wolfinbarger, S.D. Lott, M. Lerner. Geospatial Evidence in International Human Rights Litigation: Technical and Legal Considerations. Report prepared under the auspices of the AAAS Scientific Responsibility, Human Rights and Law Program. 2018.

[33] T. Harris, "Scientists and engineers as partners in protecting human rights," openDemocracy. 1 Aug 2016. https://www.opendemocracy.net/openglobalrights/theresa-harris/scientists-and-engineers-as-partners-inprotecting-human-rights

[34] Amnesty International, Autonomous Weapons Systems: Five Key Human Rights Issues for Consideration. London UK: Amnesty International Publications. 2015.30 pp.

https://amnestyfr.cdn.prismic.io/amnestyfr\%2F3258828f-1127-4b6d-ba924681f53ffe26 act3014012015english.pdf [Accessed Jan 28, 2019]

[35] A. Rachovista, "Engineering and lawyering privacy by design: understanding online privacy both as a technical and an international human rights issue," International Journal of Law and Information Technology, vol. 24, pp. 374-399, 2016.

[36] R. Hickin, "How are today's biggest tech trends affecting our human rights?" World Economic Forum. 11 Dec. 2017. https://www.weforum.org/agenda/2017/12/how-are-today-s-biggest-tech-trends-affecting-human-rights/ [Accessed Jan. 28, 2019].

[37] ABET Computing Accreditation Commission, Criteria for Accrediting Computing Programs, Optional for reviews during the 2018-2019 accreditation cycle, mandatory for reviews during the 2019-2020 accreditation cycle. Oct. 20, 2017. Baltimore MD: ABET. 14 pp.

[38] Association for Computing Machinery (ACM) and IEEE Computer Society, "Computer Engineering Curricula 2016 (CE2016): Curriculum Guidelines for Undergraduate Degree Programs in Computer Engineering,” ACM and IEEE, 151 pp., Dec. 15, 2016

[39] J.J. Britz, "Technology as a threat to privacy: ethical challenges to the information profession." http://web.simmons.edu/ chen/nit/NIT'96/96-025-Britz.html Accessed Oct. 21, 2018.

[40] S. Vallor and A. Narayan, An Introduction to Software Engineering Ethics, Markkula Center for Applied Ethics, Santa Clara University, 60 pp. https://www.scu.edu/media/ethics-center/technology-ethics/Students.pdf [Accessed Jan. 31, 2019].

[41] P. Johnson. 2017. Case Study: Privacy. ICS 314, Spring 2017. Course website. http://courses.ics.hawaii.edu/ics314s17/morea/ethics/experience-se-ethics-case-study-privacy.html [Accessed October 21, 2018].

[42] Princeton. Optimizing Schools: Case Study 3. Princeton Dialogues on AI and Ethics. 7 pp. https://aiethics.princeton.edu/wp-content/uploads/sites/587/2018/10/Princeton-AI-Ethics-Case-Study-3.pdf [Accessed Oct 21, 2018].

[43] A. Azuela and C. Herrera. Taking land around the world: International trends in the expropriation for urban and infrastructure projects. Paper commissioned by the World Bank and the Lincoln Institute of Land Policy for the Urban Research Symposium, Washington, May 2007, 42 pp.

[44] J.J. Kelly, “'We shall not be moved': urban communities, eminent domain and the socioeconomics of just compensation," 80 St. John's L. Rev. 923, 2006, 69 pp. https://scholarship.law.nd.edu/cgi/viewcontent.cgi?article=1820\&context=law faculty scholarship [Accessed Jan. 30, 2019].

[45] S.P. Calandrillo, "Eminent Domain Economics: should 'just compensation' be abolished, and would 'takings insurance' work instead?" Ohio State Law Journal, vol. 64: 451, 80 pp. https://kb.osu.edu/bitstream/handle/1811/70921/OSLJ_V64N2 0451.pdf [Accessed Jan. 30, 2019].

[46] National Society of Professional Engineers, NSPE, Engineer's Obligation to Consider Feasible Options, BER Case No. 15-12, 3 pp. https://www.nspe.org/sites/default/files/BER15-12\%20APPROVED.pdf [Accessed Jan. 30, 2019]. 
[47] C. Britschgi, Seattle transit agency wants to tear down fraternal lodge... and put up a parking garage. Jul. 28, 2017. https://reason.com/blog/2017/07/28/sound-transit-wants-to-use-eminent-domai [Accessed Oct 20, 2018]

[48] European Group on Ethics in Science and New Technologies, Future of Work, Future of Society, Brussels: European Commission. Dec. 2018, 86 pp.

https://ec.europa.eu/info/sites/info/files/research and innovation/ege/ege future-of-work_opinion_122018.pdf [Accessed Jan. 30, 2019]

[49] L. McGregor, V. Ng, A. Shaheed, The Universal Declaration of Human Rights at 70: Putting Human Rights at the Heart of the Design, Development, and Deployment of Artificial Intelligence. Colchester UK: University of Essex. 20 Dec. 2018. 48 pp. https://48ba3m4eh2bf2sksp43rq8kk-wpengine.netdna-ssl.com/wpcontent/uploads/2018/12/UDHR70_AI.pdf [Accessed Jan. 30, 2019]

[50] H. Sloan, Human Rights and IoT: The Right to Fair and Decent Work. Dec. 13, 2018. Available at: https://medium.com/iotforall/human-rights-and-iot-the-right-to-fair-and-decent-work-23a97bab25d4 [Accessed Jan. 20, 2019]

[51] R. Rincon, "What's the gender pay gap in engineering?" All Together - SWE Blog. April 202018. https://alltogether.swe.org/2018/04/pay-gap-in-engineering/ [Accessed October 20, 2018].

[52] E.A. Cech, "Ideological wage inequalities?: the technical/social dualism and the gender wage gap in engineering," Social Forces, vol. 91 (4), pp. 1147-1182, June 2013.

[53] J.R. Mihelcic, C.C. Naughton, M.E. Verbyla, Q. Zhang, R.W. Schweitzer, S.M. Oakley, E.C. Wells, L.M. Whiteford, "The grandest challenge of all: The role of environmental engineering to achieve sustainability in the world's developing regions," Environmental Engineering Science, vol. 34 (1), pp. 16-41, 2017.

[54] S. Rahimifard and H. Trollman, "UN Sustainable Development Goals: an engineering perspective," International Journal of Sustainable Engineering, vol. 11(1), pp. 1-3, 2018.

[55] J.A. Kaminsky and K.M. Faust, "Transitioning from a human right to an infrastructure service: water, wastewater, and displaced persons in Germany," Environmental Science and Technology, vol. 51, pp. 1208112088, 2017.

[56] American Association for the Advancement of Science, AAAS Statement on Scientific Freedom \& Responsibility. https://www.aaas.org/page/aaas-statement-scientific-freedom-responsibility [Accessed Jan. 30, 2019].

[57] M.K. Land and S. Hamilton, "Freedom, responsibility, and the human right to science," 2017, 6 pp. https://www.aaas.org/page/featured-articles [Accessed Jan. 30, 2019].

[58] M.S. Anderson and M.S. Frankel, "Origin and development of the 2017 AAAS Statement on Scientific Freedom and Responsibility,” 2017, 8 pp. https://www.aaas.org/page/featured-articles [Accessed Jan. 30, 2019].

[59] American Association for the Advancement of Science (AAAS), Scientific Freedom and Responsibility Articles from Science, https://www.aaas.org/page/articles-science [Jan. 30, 2019]

[60] R. Chalk, Ed. Science, Technology, and Society: Emerging Relationships. Papers from SCIENCE, 1949-1988. Washington DC: The American Association for the Advancement of Science. 264 pp.

[61] National Science Foundation, "Perspectives on Broader Impacts," NSF 15-008 https://www.nsf.gov/od/oia/publications/Broader_Impacts.pdf [Accessed Jan. 30, 2019].

[62] M.A. Edwards and S. Roy, "Academic research in the $21^{\text {st }}$ century: maintaining scientific integrity in a climate of perverse incentives and hypercompetition," Environmental Engineering Science, vol. 34 (1), pp. 51-61, 2017.

[63] Youth for Human Rights. What are human rights? https://www.youthforhumanrights.org/what-are-humanrights/universal-declaration-of-human-rights/articles-1-15.html [Accessed Jan 20, 2019].

[64] N. Canney and A. Bielefeldt, "A framework for the development of social responsibility in engineers," International Journal of Engineering Education, vol. 31 (1B), pp. 414-424, 2015.

[65] L. Carter, "Making ethical engineers: Engineers for social responsibility," Proceedings of the 2011 Australasian Association of Engineering Education Conference, Fremantle, Western Australia, 2011. pp. 50-54.

[66] D.R. Brodeur, "Mentoring young adults in the development of social responsibility," Australasian Journal of Engineering Education, vol. 19 (1), pp. 13-25, 2013.

[67] IEEE, Ethically Aligned Design: A Vision for Prioritizing Human Well-being with Autonomous and Intelligent Systems, Version 2 - For Public Discussion, 2018. 266 pp.

[68] C. Cath and L. Floridi, "The design of the internet's architecture by the Internet Engineering Task Force (IETF) and human rights," Science and Engineering Ethics, vol. 23, pp. 449-468, 2017.

[69] S. Iqbal, X. Zang, Y. Zhu, Y.Y. Chen, J. Zhao. "On the impacts of MOOCs on engineering education," 2014 IEEE International Conference on MOOC, Innovation and Technology in Education (MITE), Dec.19-20, 2014, Patiala, India. 
[70] W.J. Bennett and D. Wilezol. Is College Worth It? Nashville: Thomas Nelson Inc. 2013.

[71] College Board, Trends in College Pricing. https://trends.collegeboard.org/college-pricing [Accessed Jan. 31, 2019].

[72] K. Blagg and E. Blom, "Evaluating the return on investment in higher education," Urban Institute, Sept. 2018, $20 \mathrm{pp}$.

[73] J.G. Altonji and S.D. Zimmerman, The Costs of and Net Returns to College Major, Working Paper 23029. National Bureau of Economic Research, Cambridge MA, Jan. 2017. https://www.nber.org/papers/w23029.pdf [Accessed Jan. 31, 2019].

[74] M.H. Forbes, A.R. Bielefeldt, J.F. Sullivan, R.L. Littlejohn. "Divergent requirements for technical and nontechnical coursework in undergraduate engineering programs," International Journal of Engineering Education, vol. 33 (1A), pp. 162-174, 2017.

[75] M.H. Forbes, A.R. Bielefeldt, J.F. Sullivan, D. Chaker, "Exploring impacts of flexible, balanced engineering program curricula." Proceedings of the American Society for Engineering Education Annual Conference \& Exposition, Paper ID \#17906, 15 pp. 2017.

[76] Best College Values. The 25 Most Affordable Engineering Bachelors Degree Programs. http://www.bestcollegevalues.org/most-affordable-engineering-bachelors-degree-programs/ [Accessed Jan. 31, 2019].

[77] B.A. Myers, Evaluating Admission Practices as Potential Barriers to Creating Equitable Access to Undergraduate Engineering Education. 2016. Civil Engineering Graduate Dissertation, University of Colorado Boulder. Available at: https://scholar.colorado.edu/cven_gradetds/27 [Accessed Jan. 30, 2019]

[78] B.M. Holloway, T. Reed, P.K. Imbrie, K. Reid, "Research-informed policy change: A retrospective on engineering admissions." Journal of Engineering Education, vol. 103 (2), pp. 274-301, April 2014.

[79] G. Attiyeh and R. Attiyeh, "Testing for bias in graduate school admissions," The Journal of Human Resources, vol. 32 (3), pp. 524-548, Summer 1997.

[80] M.J. Perry, "Will previously girls-only summer STEM camps really now be welcoming to boys if the program names aren't changed?" AEIdeas Public Policy Blog. March 12, 2018. http://www.aei.org/publication/willpreviously-girls-only-summer-stem-camps-really-now-be-welcoming-to-boys-if-the-program-names-arentchanged/ [Accessed Jan. 30, 2019]

[81] A. Hartocollis, "As justices weight affirmative action, Michigan offers an alternative." New York Times, Jan. 4, 2016. https://www.nytimes.com/2016/01/05/us/affirmative-action-supreme-court-michigan.html [Accessed Jan. 30, 2019]

[82] J. Cuseo, "Liberal arts \& general education: What it means to be a well-educated person in the $21^{\text {st }}$ century," Thriving in College \& Beyond: Research-Based Strategies for Academic Success and Personal Development, $4^{\text {th }}$ Edition, Eds. J.R. Cuseo, A. Thompson, M. Campaga, V.S. Fecas. Kendall Hunt Publishing, 2016.

[83] Association of American Colleges \& Universities (AAC\&U), The Well-Being and Flourishing of Students, Bringing Theory to Practice Project, Washington DC: AACU, 2013. Available online: https://www.aacu.org/sites/default/files/files/CLDE/BTtoPWellbeingInitiative.pdf [Accessed Mar. 13, 2019]

[84] J.L. Buller, "The two cultures of higher education in the twenty-first century and their impact on academic freedom," AAUP Journal of Academic Freedom, vol. 5, 8 pp, 2014.

[85] D. Nieusma, "Engineering, social justice, and peace: Strategies for pedagogical, curricular, and institutional reform," Proceedings of the American Society for Engineering Education (ASEE) Annual Conference \& Exposition, Vancouver BC, June 26-29, 2011. 12 pp.

[86] T. H. Colledge, Convergence: Philosophies and Pedagogies for Developing the Next Generation of Humanitarian Engineers and Social Entrepreneurs, IJSLE, 2012.

[87] F. Monteiro, C. Leite, C. Rocha, "From the dominant engineering education perspective to the aim of promoting service to humanity and the common good: the importance of rethinking engineering education," European Journal of Engineering Education, DOI: 10.1080/03043797.2018.1435630, 15 pp, 2018.

[88] E.A. Cech, "Culture of disengagement in engineering education?" Science, Technology \& Human Values, vol. 39 (1), pp. 42-72, 2014.

[89] S. Hertel and A. MacKay, "Engineering and human rights: Teaching across the divide," Business and Human Rights Journal, vol 1 (1), pp. 159-164, 2016.

[90] G.M. Willems, “A comparative approach to human rights education,” Education and Society, vol. 24 (2), pp. 87-97, 2006. 